\title{
The first report of the prevalence of Nosema ceranae in Bulgaria
}

\author{
Rositsa Shumkova ${ }^{1}$, Ani Georgieva ${ }^{2}$, Georgi Radoslavov ${ }^{3,4}$, Daniela Sirakova ${ }^{3}$, Gyulnas Dzhebir ${ }^{4}$, Boyko \\ Neov $^{3}$, Maria Bouga ${ }^{5}$, Peter Hristov ${ }^{\text {Corresp. } 3,4}$ \\ ${ }^{1}$ Agricultural and Stockbreeding Experimental Station, Agricultural Academy, Smolyan, Bulgaria \\ 2 Department of Pathology, Institute of Experimental Morphology, Pathology and Morphology and Anthropology with Museum, Bulgarian Academy of \\ Sciences, Sofia, Bulgaria \\ 3 Department of Animal Diversity and Resources, Institute of Biodiversity and Ecosystem Research, Bulgarian Academy of Sciences, Sofia, Bulgaria \\ 4 Department of Structure and Function of Chromatin, Institute of Molecular Biology, Bulgarian Academy of Sciences, Sofia, Bulgaria \\ 5 Laboratory of Agricultural Zoology and Entomology, Agricultural University of Athens, Athens, Greece \\ Corresponding Author: Peter Hristov \\ Email address: peter_hristoff@abv.bg
}

Nosema apis and Nosema ceranae are the two main microsporidian parasites causing nosematosis in honey bee Apis mellifera. The aim of the present study is to investigate the presence of Nosema apis and Nosema ceranae in the area of Bulgaria. The 16S (SSU) rDNA gene region was chosen for analysis. A duplex PCR assay was performed on 108 honey bee samples from three different parts of the country (South, North and West Bulgaria). The results showed that the samples from the northern part of the country were with the highest prevalence (77.2\%) for Nosema ceranae while those from the mountainous parts (the Rodopa Mountains, South Bulgaria) were with the lowest rate (13.9\%). Infection with Nosema apis alone and co-infection N. apis/N. ceranae were not detected in any samples. These findings suggest that Nosema ceranae is the dominant species in the Bulgarian honey bee. It is not known when the introduction of Nosema ceranae in Bulgaria has occurred, but like in the rest of the world, this species has become the dominant one in Bulgarian Apis mellifera. In conclusion, this is the first report for molecular detection of Nosema infection of honey bee in Bulgaria. The results showed that $N$. ceranae is the main Nosema species in Bulgaria. 
Title: The first report of the prevalence of Nosema ceranae in Bulgaria

3 Rositsa Shumkova $^{2,}$, Ani Georgieva ${ }^{3}$, Georgi Radoslavov ${ }^{1,4}$, Daniela Sirakova ${ }^{1}$, Gyulnas Dzhebir ${ }^{4}$,

4 Boyko Neov ${ }^{1}$, Maria Bouga ${ }^{5}$, Peter Hristov ${ }^{1,4^{*}}$

$5{ }^{1}$ Department of Animal Diversity and Resources, Institute of Biodiversity and Ecosystem

6 Research, Bulgarian Academy of Sciences, Sofia, Bulgaria;

$7{ }^{2}$ Agricultural and Stockbreeding Experimental Station, Agricultural Academy, Smolyan, 8 Bulgaria;

$9{ }^{3}$ Department of Pathology, Institute of Experimental Morphology, Pathology and Morphology

10 and Anthropology with Museum, Bulgarian Academy of Sciences, Sofia, Bulgaria;

$11{ }^{4}$ Department of Structure and Function of Chromatin, Institute of Molecular Biology, Bulgarian

12 Academy of Sciences, Sofia, Bulgaria;

$13{ }^{5}$ Laboratory of Agricultural Zoology and Entomology, Agricultural University of Athens, Athens,

14 Greece

$15 *$ Corresponding author: Peter Hristov, Department of Animal Diversity and

16 Resources, Institute of Biodiversity and Ecosystem Research, Bulgarian

17 Academy of Sciences, “cad. G. Bonchev” tr., B1. 25, Sofia, 1113, Bulgaria, Tel:

18 + 3592979 2327; E-mail: peter_hristoff@abv.bg

\section{Abstract}

20 Nosema apis and Nosema ceranae are the two main microsporidian parasites causing 21 nosematosis in honey bee Apis mellifera. The aim of the present study is to investigate the 22 presence of Nosema apis and Nosema ceranae in the area of Bulgaria. The 16S (SSU) rDNA 
23 gene region was chosen for analysis. A duplex PCR assay was performed on 108 honey bee

24 samples from three different parts of the country (South, North and West Bulgaria). The results

25 showed that the samples from the northern part of the country were with the highest prevalence

$26(77.2 \%)$ for Nosema ceranae while those from the mountainous parts (the Rodopa Mountains,

27 South Bulgaria) were with the lowest rate (13.9\%). Infection with Nosema apis alone and co-

28 infection $N$. apis/N. ceranae were not detected in any samples. These findings suggest that

29 Nosema ceranae is the dominant species in the honey bee in Bulgaria. It is not known when the

30 introduction of Nosema ceranae in Bulgaria has occurred, but like in the rest of the world, this

31 species has become the dominant one in Bulgarian Apis mellifera.

32 In conclusion, this is the first report for molecular detection of Nosema infection of honey bee

33 in Bulgaria. The results showed that N. ceranae is the main Nosema species in Bulgaria.

\section{Introduction}

35 The Western honey bee (Apis mellifera L., Hymenoptera: Apidae) is a species of crucial

36 economic, agricultural and environmental importance. The biological significance of bees is

37 rooted in the fact that they are main pollinators in the natural environment (Barrios et al., 2016;

38 Ballantyn et al., 2017). About $80 \%$ of the pollination of entomophilous plants is carried out by

39 Apis mellifera. In all crops, active pollination significantly increases their yields (Partap, 2011).

40 On the other hand honey bees are a valuable economic asset due to the ensemble of their

41 products which includes honey, bee pollen, propolis, royal jelly, and bee venom, used by humans

42 for food and treatment (Pasupuleti et al., 2017; Sforcin et al., 2017).

43 Bulgaria has long-standing traditions in the production of honey and bee products, a

44 precondition for which is the varied and rich vegetation of the Balkan Peninsula suitable for the

45 production of honey and also the favorable natural, climatic and ecological conditions.

46 Honey bee colonies suffer from numerous pathogens. These include various bacteria, viruses,

47 fungi and endo- and ecto-parasites. Some of them, microsporidians, are obligate intracellular 
48 parasites belonging to the kingdom Fungi (Keeling and McFadden, 1998; Hirt et al., 1999; Sina

49 et al., 2005). Nosema is a microsporidian genus causing an infection called Nosemosis of adult

50 honey bees (Klee et al., 2007). Only two main species of Nosema causing infection in Apis

51 mellifera have been recognized - Nosema apis (Zander, 1909) and Nosema ceranae (Fries et al.,

52 1996). It is well known that $N$. apis is specific for the Western honey bee, Apis mellifera L.,

53 whilst the Eastern honey bee Apis cerana harbours Nosema ceranae (Fries et al., 1996).

54 However, many recent investigations have revealed that $N$. ceranae is not restricted only to $A$.

55 cerana, but it transferred to A. mellifera, and even became a dominant species in many parts in

56 the world (Klee et al., 2007; Paxton et al., 2007; Chen et al., 2008; Invernizzi et al., 2009;

57 Tapaszti et al., 2009; Stevanovic et al., 2010; Gajger et al., 2010; Ansari et al., 2017; Papini et al.,

58 2017). The exact time and transmission route of transfer of $N$. ceranae from $A$. cerana to $A$.

59 mellifera is not known . It is possible that during the last decades, the rapid, long-distance

60 dissemination of $N$. ceranae is likely due to the transport of infected honey bees and/or by the

61 increased mobility of people, goods and livestock. Recently, a so called "Colony Collapse

62 Disorder" (CCD) disease has been described in the United States (Chen et al., 2008) and Europe

63 (Topolska et al., 2008). The Nosema ceranae was suspected to one of the contributor to this

64 illness, especially winter colony loses (Klee et al., 2007).

65 There are two main techniques for identifying Nosema species - microscopic and molecular.

66 The microscopic methods such as Light microscopy, Giemsa and Toluidine staining, and

67 Transmission electron microscopy were introduced first (Fries et al., 2013); but they are still a

68 valuable, relatively cheap and simple method for screening and identification of Nosema

69 infection. According to Ptaszyńska et al. (2014), N. ceranae spores seem to be more sculptured

70 with deeper ornamentation than those of $N$. apis. Despite the fact that $N$. apis and N. ceranae

71 spores are morphologically different, in case of low rate of infection or presence of vegetative

72 forms of Nosema, differentiation between spores of $N$. apis and N. ceranae is very difficult This 
73 requires the search for methods that are more sensitive. Therefore, various molecular methods

74 have been developed. Those include mainly PCR techniques (conventional or duplex PCR, PCR-

75 RFLP, qPCR) (Fries et al., 2013) involving usually a wide range of species-specific PCR primers

76 (Martín-Hernández et al., 2007; Klee et al. 2007; Chen et al. 2008).

77 Until now, there has been no data regarding the distribution of $N$. apis and $N$. ceranae

78 throughout Bulgaria as well as information if $N$. ceranae has become a dominant species,

79 although Nosema infection for the surrounding Balkan countries is well studied (Stevanovic et

80 al., 2010; Whitaker et al., 2010; Hatjina et al., 2011).

81 The main goal of the current study is to investigate and determine the presence and

82 distribution of the two different Nosema spp. in the Bulgarian honey bee.

\section{Materials and Methods}

84 Sample collection. A total of 108 honey bee samples were collected from three different parts

85 in the country: Rousse district (North Bulgaria, $N=44$ ), Sofia district (West Bulgaria, $N=28$ ) and

86 Smolyan district (South Bulgaria, N=36), (Table 1, Fig. 1) in April-May 2017. There is no bias

87 concerning the obtained honey bee samples. The first two regions are characterized by their low-

88 lying and generally flat plains, while the last region is situated in the Rodopa Mountains.

89 Sampling was done according to the guidelines of the Office International des Epizooties (2008).

90 None of the honey bee colonies were treated against Nosema infection for at least 6 months. In

91 each hive, five adult worker honey bees were randomly selected at the entrance of the hive or on

92 frames away from the brood nest. The honey bees were placed in a falcon tube, put in a cooler

93 bag and stored at $-20{ }^{\circ} \mathrm{C}$ prior to analysis.

94 DNA extraction. Briefly, prior to DNA extraction, the abdomen of a single bee was cut off

95 with scissors, mechanically homogenized with a cell lysis buffer and centrifuged for 1 min at 15

$96000 \mathrm{rpm}$. Total DNA was isolated by using GeneMATRIX Tissue and Bacterial DNA purification 
97 Kit (Cat. No. E3551-01, EURx Ltd., Poland) according to the manufacturer instructions. Shortly,

98 the pellet was resuspended in a cell lysis buffer (a component of a DNA purification kit);

99 proteinase $\mathrm{K}$ was added and incubated overnight at $56^{\circ} \mathrm{C}$. The extracted DNA was resuspended

100 in $50 \mu \mathrm{L}$ of elution buffer. The DNA concentration was determined spectrophotometrically and

101 the quality of the DNA samples was examined on 1\% agarose gel electrophoresis stained with

102 Greensafe premium (Cat. No. MB13201, Nzytech, Portugal). The purified DNA was stored at -

$10320{ }^{\circ} \mathrm{C}$ until PCR assay.

104 Gene selection and PCR amplification. The small subunit (16S) ribosomal RNA gene was

105 chosen for molecular identification of Nosema ceranae and Nosema apis. A fragment of this gene

106 was amplified in both Nosema species using primers designed by Martín-Hernández et al. (2007).

107 321APIS-FOR (5'-GGGGGCATGTCTTTGACGTACTATGTA-3'; 321APIS - REV (5'-

108 GGGGGGCGTTtAAAATGGAAACAACTATG-3') for Nosema apis and 218MITOC - FOR

109 (5'-CGGCGACGATGTGATATGAAAATATTAA-3'); 218MITOC - REV (5'-

110 CCCGGTCATTCTCAAACAAAAAACCG- 3’') for N. ceranae.

111 Both primer sets were used together for performing a duplex PCR for identification and

112 discrimination of Nosema species.

113 The expected number of the amplified products in $N$. ceranae using the 218MITOC primers

114 can be either 218 or 219 depending on the sequences for $N$. ceranae available in the GenBank

115 database (http://www.ncbi.nlm.nih.gov/) (Martín-Hernández et al., 2007). In the case of N. apis,

116 the expected size of the amplicon using the 321APIS primers was $321 \mathrm{bp}$. In addition, a negative

117 control was included for all PCR reactions. As a positive control, cytochrome c-oxidase gene

118 (CoI2) of Apis mellifera was used in all studied samples. The sequence of primers used for

119 positive control was CoI2-F (5'-CCTGATATAGCATTTCCTCG-3') and CoI2-R (5'-

120 TGTGAATGATCTAAAGGTGG-3') designed on the base of the known mitochondrial genome

121 of $A$. m. ligustica (Acc. No. L06178, Crozier and Crozier, 1993). The PCR mixtures contained 25 
$122 \mu \mathrm{L}$ of NZYTaq $2 \times$ Colourless Master Mix (Cat. No. MB04002, Nzytech, Portugal), $0.4 \mu \mathrm{M}$ of

123 each species-specific primer (FOR/REV), $1 \mu \mathrm{L}$ of template DNA and PCR water (Cat. No.

124 E0211-01, EURx Ltd., Poland) in a total volume of $50 \mu \mathrm{L}$. All PCR reactions were carried out

125 using a Little Genius thermocycler (BIOER Technology Co., Ltd) under the following conditions:

126 initial denaturation at $94^{\circ} \mathrm{C}$ for $5 \mathrm{~min} ; 30$ cycles (denaturation at $94{ }^{\circ} \mathrm{C}$ for $30 \mathrm{~s}$; primer annealing

127 at $50{ }^{\circ} \mathrm{C}$ for $30 \mathrm{~s}$; extension at $72{ }^{\circ} \mathrm{C}$ for $1 \mathrm{~min}$ ) and final extension at $72{ }^{\circ} \mathrm{C}$ for $10 \mathrm{~min}$. PCR

128 products were visualized on a $2 \%$ agarose gel with Greensafe premium (Cat. No. MB13201,

129 Nzytech, Portugal). The fragment size was determined using Gene-Ruler ${ }^{\mathrm{TM}} 100$ bp Ladder Plus

130 (Cat. No. SM0323, ThermoFisher Scientific Inc.).

131 Sequence analysis

132 The successfully amplified products for Nosema (20 samples) were purified by a PCR

133 purification kit (Gene Matrix, PCR clean-up kit, EURx, Poland) and sequenced in both directions

134 by a PlateSeq kit (Eurofins Genomics Ebersberg, Germany). The obtained sequences were

135 deposited in GenBank under accession no.: MG657260.

$136 \quad$ Results

137 Duplex PCR with species-specific primers (321APIS-FOR/REV and 218MITOC-FOR/REV)

138 produced PCR products in 57 samples out of 108 analyzed (52.8\% successful amplifications),

139 while 51 samples failed to produce a PCR product (47.2\%). There were no PCR products in the

140 negative controls. The results from the obtained sequences support identity only to Nosema

141 ceranae species.

142 From all investigated samples only Nosema ceranae infection was detected. The highest level

143 of infection was observed in North Bulgaria. From all 44 investigated samples, 34 (77.2\%) were

144 Nosema positive (Table 1). In the west part of the country (Sofia district), Nosema positive

145 samples were detected in 18 from all 28 studied samples (64.3\%). The lowest level of infections

146 was found in the honey bee samples from the mountainous part of the country (Smolyan district, 
147 the Rodopa Mountains). From all 36 investigated samples, only 5 (13.9\%) were Nosema positive.

148 Surprisingly, in all the studied samples from three different regions of the country only Nosema

149 ceranae was found. The presence of Nosema apis as well as co-infections $N$. apis/N. ceranae

150 were not detected (Table 1). Moreover, the honey bee samples from the flat part of the country

151 (Sofia and Rousse districts) had a higher prevalence of $N$. ceranae infection as compared with

152 samples obtained from the mountainous part (Smolyan district).

\section{Discussion}

154 In the current study, we have presented for the first time molecular identification of two

155 Nosema spp. and their distribution in Bulgaria. The results indicate the presence of N. ceranae in

15657 of 108 investigated samples, which suggests the dominance of $N$. ceranae in all investigated

157 regions. The results of many studies from the Balkan countries have indicated that N. ceranae

158 displaces N. apis (Stevanovic et al., 2010; Whitaker et al., 2010; Hatjina et al., 2011; Gajger et

159 al., 2010) (Fig. 1). One reasonable question is why this introduced parasite (N. ceranae) has become

160 in a short time the dominant species worldwide? Concerning the virulence of the two Nosema spp.,

161 the results are contradictory. It is an interesting fact that in many European countries numerous

162 studies report that $N$. ceranae is more virulent and thus possesses a competitive advantage in

163 compared to N. apis (Klee et al., 2007; Paxton et al., 2007; Forsgren and Fries, 2010). Contrary to

164 this, more recent research, performed mainly in the USA, does not support these observations (Huang

165 et al., 2015; Milbrath et al., 2015). These studies suggest that the US honey bees may be less

166 susceptible to $N$. ceranae infections than European bees or that the US isolates of the pathogen are

167 less infective and less virulent than European isolates.

168 These findings are a suitable way to explain our results. We found that $N$. ceranae infection

169 prevailed in honey bee colonies from the flat part of the country (Rousse and Sofia district), while in

170 the mountainous part (Smolyan district, the Rodopa Mountains) the prevalence was the lowest (Table

171 1). Different subspecies of Apis mellifera are raised in the flat and in mountainous regions. A. m. 
172 macedonica is considered to be a native honey bee for Bulgaria (Ruttner, 1988). More than three

173 decades ago, A. m. ligustica, A. m. carnica and A. m. caucasica were introduced and were reared in

174 Bulgaria (Bouga et al., 2011). These subspecies are disseminated mainly in the flat regions of the

175 country. On the other hand, in Bulgaria exists a local honey bee subspecies called A. m. rodopica,

176 geographically distributed only in the Rodopa Mountains massive (Petrov, 1995; Bouga et al., 2011;

177 Ivanova et al., 2012; Nikolova and Ivanova, 2012). Our previous investigation on mitochondrial

178 heredity have revealed that $A . m$. rodopica is a distinct subspecies concerning malfunction of COI

179 protein in compared to other honey bee subspecies reread in Bulgaria (Radoslavov et al., 2017).

180 According to Petrov (2010), A. m. rodopica possesses a lot of advantages in compared to the

181 introduced subspecies - good adaptation to the specific local climatic conditions, resistance numerous

182 diseases etc. These findings might explain the differences in the prevalence of $N$. ceranae in the

183 different areas since different subspecies of bees are reared in each area. Another fact, which may

184 explain the low rate of infection of $A . m$. rodopica, is the long geographical isolation of this

185 subspecies. Moreover, the beekeepers in this region are encouraged to raise this local honey bee and

186 even not to allow genetic introgression with other subspecies in Bulgaria.

187 Another fact which may explain the high rate of infestation with $N$. ceranae in honey bee colonies

188 from the plain regions in compared to the mountainous regions of the country is the different climatic

189 conditions in these places. The Rodopa Mountains climate is rather colder than the other two

190 investigated regions. This determine the later development of honey bee colonies (May-August).

191 Moreover, malfunction of COI protein in A. m. rodopica may associated with lower mitochondrial

192 respiration metabolism, which may determinate and lower activity of honey bees. Many papers have

193 discussed that warmer climatic conditions favored prevalence of $N$. ceranae (Tapaszty et al., 2009;

194 Stevanovic et al., 2011), whereas N. apis remains more prevalent in colder climates (Budge et al.,

195 2010; Gisder et al., 2010; Natsopoulou et al., 2015).

\section{Conclusion}


197 This is the first report of the distribution of $N$. ceranae of honey bee colonies in Bulgaria. We

198 found that $N$. ceranae is the dominant species in the Bulgarian honey bee. A local honey bee $A . m$.

199 rodopica reared in the Rodopa Mountains seems to be more resistant in compared to the introduced

200 species. Because of this, local honey bees should be kept as a part of the genetic diversity and the 201 related conservation activities.

\section{References}

203 1. Ansari MJ, Al-Ghamdi A, Nuru A, Khan KA, Alattal Y. 2017. Geographical distribution

204 and molecular detection of Nosema ceranae from indigenous honey bees of Saudi Arabia.

205 Saudi Journal of Biological Sciences. 24: 983-991. DOI: 10.1016/j.sjbs.2017.01.054.

206 2. Ballantyne G, Baldock KCR, Rendell L, Willmer PG. 2017. Pollinator importance

207 networks illustrate the crucial value of bees in a highly speciose plant community.

208 Scientific Reports, 7:8389. DOI:10.1038/s41598-017-08798-x.

209 3. Barrios B, Pena SR, Salas A, Koptur S. 2016. Butterflies visit more frequently, but bees

210 are better pollinators: the importance of mouthpart dimensions in effective pollen removal

211 and deposition. AoB Plants, 8:plw001. DOI: 10.1093/aobpla/plw001.

212 4. Bouga M, Alaux C, Bienkowska M, Büchler R, Carreck NL, Cauia E, Wilde J. 2011. A

213 review of methods for discrimination of honey bee populations as applied to European

214 beekeeping. Journal of Apicultural Research, 50: 51-84. DOI: 10.3896/IBRA.1.50.1.06.

215 5. Budge G, Powell M, Roberts K, Adams I, Jones B, Marris G, Laurenson L, Wilkins S,

216 Pietravalle S, Brown M. 2010. What has Nosema got to do with losses? Monitoring both

217 Nosema species in the UK. In Proceedings of the 4th European Conference of Apidology

218 (p. 48). Ankara - Turkey. 
219 6. Chen Y, Evans JD, Smith IB, Pettis JS. 2008. Nosema ceranae is a long-present and widespread microsporidean infection of the European honey bee (Apis mellifera) in the United States. Journal of Invertebrate Pathology 97: 186-188. DOI: 10.1016/j.jip.2007.07.010

7. Crozier, R.H., and Crozier YC. 1993. The mitochondrial genome of the honey bee Apis mellifera: Complete sequence and genome organization. Genetics 133: 97-117.

8. Evans JD, Chen YP, Cornman RS, De La Rua P, Foret S, Foster L, Genersch E, Gisder S, Jarosch A, Kucharski R, Lopez D, Lun CM, Moritz RFA, Maleszka R, Muñoz I, Pinto MA, Schwarz RS. 2013 Standard methodologies for molecular research in Apis mellifera. In V Dietemann; J D Ellis; P Neumann (Eds) The COLOSS BEEBOOK, Volume I: standard methods for Apis mellifera research. Journal of Apicultural Research 52(4).

9. Forsgren E., Fries I. 2010. Comparative virulence of Nosema ceranae and Nosema apis in individual European honey bees. Veterinary Parasitolology 170: 212-217. DOI: 10.1016/j.vetpar.2010.02.010.

10. Fries I, Chauzat MP, Chen YP, Doublet V, Genersch E, Gisder S, Higes M, McMahon

11. Fries I, Feng, da Silva, Slemenda SB, Pieniazek NJ. 1996. Nosema ceranae n. sp. DP, Martín-Hernández R, Natsopoulou M, Paxton RJ, Tanner G, Webster TC, Williams GR. 2013. Standard methods for Nosema research, Journal of Apicultural Research 52: 1(Microspora, Nosematidae), morphological and molecular characterization of a microsporidian parasite of the Asian honey bee Apis cerana (Hymenoptera, Apidae), European Journal of Protistology 32: 356-365. DOI: 10.1016/S0932-4739(96)80059-9.

12. Gajger T, Vugrek O, Petrinec Z, Grilec D, Tomljanovic Z. 2010. Detection of Nosema ceranae in honey bees from Croatia. Journal of Apicultural Research 49: 340-341. DOI: 10.3896/IBRA.1.49.4.08. 
244 13. Gisder S, Hedtke K, Möckel N, Frielitz M-C, Linde A, Genersch E. 2010. Five-year 245 cohort study of Nosema spp. in Germany: does climate shape virulence and assertiveness 246 of Nosema ceranae? Applied and Environmental Microbiology 76: 3032-3038. DOI: 10.1128/AEM.03097-09.

14. Hirt RP, Logsdon JM, Healy B, Dorey MW, DoolittleWF, Embley TM. 1999. Microsporidia are related to fungi: evidence from the largest subunit of RNA polymerase II and other proteins, Proceedings of the National Academy of Sciences (USA) 96: 580585. DOI: $10.1073 /$ pnas.96.2.580.

15. Huang WF, Solter L, Aronstein K, Huang Z. 2015. Infectivity and virulence of Nosema ceranae and Nosema apis in commercially available North American honey bees. Journal of Invertebrate Pathology 124: 107-113. DOI: 10.1016/j.jip.2014.10.006.

16. Invernizzi C, Abud C, Tomasco IH, Harriet J, Ramallo G, Campá J, Katz H, Gardiol G, Mendoza Y. 2009. Presence of Nosema ceranae in honeybees (Apis mellifera) in Uruguay. Journal of Invertebrate Pathology 101: 150-153. DOI: 10.1016/j.jip.2009.03.006.

17. Ivanova E, Staykova T, Stoyanov I, Petrov P. 2012. Allozyme genetic polymorphism in Bulgarian honey bee (Apis mellifera L.) populations from the south-eastern part of the Rhodopes. Journal of BioScience and Biotechnology 1: 45-49. http://www.jbb.uniplovdiv.bg.

18. Keeling PJ., McFadden GI. 1998. Origins of microsporidia. Trends Microbiolology 6: 1923. DOI: $10.1016 / \mathrm{S} 0966-842 \mathrm{X}(97) 01185-2$.

19. Klee J, Besana AM, Genersch E, Gisder S, Nanetti A, Tam DQ, Chinh TX, Puerta F, Ruz J.M, Kryger P, Message D, Hatjina F, Korpela S, Fries I, Paxton RJ. 2007. Widespread dispersal of the microsporidian Nosema ceranae, an emergent pathogen of the western honey bee, Apis mellifera, Journal of Invertebrate Pathology 96: 1-10. DOI: 
20. Martín-Hernández R, Meana A, Prieto L, Martínez- Salvador A, Garrido-Bailon E, Higes M. 2007. Outcome of colonization of Apis mellifera by Nosema ceranae, Applied and Environmental Microbiology 73: 6331-6338. DOI: 10.1128/AEM.00270-07.

21. Milbrath MO, van Tran T, Huang WF, Solter LF, Tarpy DR, Lawrence F, Huang ZY, 2015. Comparative virulence and competition between Nosema apis and Nosema ceranae in honey bees (Apis mellifera). Journal of Invertebrate Pathology 125, 9-15. DOI: 10.1016/j.jip.2014.12.006.

22. Natsopoulou M, McMahon D, Doublet V, Bryden J, Paxton R. 2015. Interspecific competition in honeybee intracellular gut parasites is asymmetric and favours the spread of an emerging infectious disease. Proceedings of the Royal Society B: Biological Sciences. 282 20141896. DOI: 10.1098/rspb.2014.1896.

23. Nikolova S, Ivanova E. 2012. Genetic variability in a local Bulgarian honey bee population. Acta Zoologica Bulgarica 64: 199-204.

24. Office International des Epizooties (OIE). 2008 Manual of Standards for Diagnostic Test and Vaccines, http:/www.oie.int/eng/normes/ mmanual/2008/ (accessed on 20 Nov. 2009).

25. Papini R, Mancianti F, Canovai R, Cosci F, Rocchigiani G, Benelli G, Canale A. 2017. Prevalence of the microsporidian Nosema ceranae in honeybee (Apis mellifera) apiaries in Central Italy. Saudi Journal of Biological Sciences 24: 979-982. DOI: 10.1016/j.sjbs.2017.01.010.

26. Partap U. 2011. The Pollination Role of Honeybees. In: Hepburn H., Radloff S. (eds) Honeybees of Asia. Springer, Berlin, Heidelberg, pp. 227-255. DOI: 10.1007/978-3-642- 
292

293

294

295

296

297

298

27. Pasupuleti VR, Sammugam L, Ramesh N, Gan SH. 2017. Honey, Propolis, and Royal Jelly: A Comprehensive Review of Their Biological Actions and Health Benefits. Oxidative Medicine and Cellular Longevity, 2017 :1259510. DOI:10.1155/2017/1259510.

28. Paxton RJ, Klee J, Korpela S, Fries I. 2007. Nosema ceranae has infected Apis mellifera in Europe since at least 1998 and may be more virulent than Nosema apis. Apidologie 38: 558-565. DOI: 10.1051/apido:2007037.

29. Petrov P. 1995. Bulgarian honey bee Apis mellifica rodopica and it race standard. Agrarian University of Plovdiv, Scientific Works, XL, 317-319.

30. Petrov P. 2010. Organization and principles of queen selection and rearing in Bulgaria. Biotechnology and Biotechnological Equipment 24: 375-378. DOI: $10.1080 / 13102818.2010 .10817867$.

31. Ptaszyńska AA, Borsuk G, Mułenko W, Demetraki-Paleolog J. 2014. Differentiation of Nosema apis and Nosema ceranae spores under Scanning Electron Microscopy (SEM). Journal of Apicultural Research, 53(5): 537-544. DOI: 10.3896/IBRA.1.53.5.02.

32. Radoslavov G, Hristov P, Shumkova R, Mitkov I, Sirakova D, Bouga M. 2017. A specific genetic marker for the discrimination of native Bulgarian honey bees (Apis mellifera rodopica): Duplication of coI gene fragment. Journal of Apicultural Research, 56(3): 196 - 202. DOI:10.1080/00218839.2017.1307713.

33. Ruttner F. 1988. Biogeography and taxonomy of honey bees. Berlin: Springer-Verlag. ISBN 978-3-642-72649-1

34. Sina M, Alastair G, Farmer M, Anderse R., Anderson O, Barta J, Bowser S, Brugerolle G, Fensome R, Frederico S, James T, Karpov S, Kugrens P, Krug J, Lane C, Lewis L, Lodge J, Lynn D, Mann D, Maccourt R, Mendoza L, Moestrup O, Mozley S, Nerad T, Sheare, T, Smirnov A, Spiegel F, Taylor M. 2005. The new higher level classification of eukaryotes 
316 with emphasis on the taxonomy of Protists. Journal of Eukaryotic Microbiology, 52: 399-

317 451. DOI:10.1111/j.1550-7408.2005.00053.x

318 35. Sforcin JM, Bankova V, Kuropatnicki AK. 2017. Medical benefits of honeybee products.

319 Evidence-based complementary and alternative medicine: eCAM. 2017:2702106.

$320 \quad$ DOI: $10.1155 / 2017 / 2702106$.

321 36. Stevanovic J, Stanimirovic Z, Genersch E, Kovacevic SR, Ljubenkovic J, Radakovic M,

322 Aleksic N. 2011. Dominance of Nosema ceranae in honey bees in the Balkan countries in

323 the absence of symptoms of colony collapse disorder. Apidologie. 42:49-58. DOI:

$324 \quad$ 10.1051/apido/2010034.

325 37. Tapaszti Z, Forgách P, Kovágó C, Békési L, Bakony, T, Rusvai M. 2009. First detection

326 and dominance of Nosema ceranae in Hungarian honeybee colonies. Acta Veterinaria

327 Hungarica 57: 383-388. DOI: 10.1556/AVet.57.2009.3.4.

328 38. Topolska G, Gajda A, Hartwig A. 2008. Polish honey bee colony-loss during the winter of 329 2007/2008. Journal of Apicultural Science. 52: 95-104.

330 39. Whitaker J, Szalanski, AL, Kence M. 2011. Molecular detection of Nosema ceranae from

331 Turkish honey bees. Apidologie 42: 174-180. DOI: 10.1051/apido/2010045.

332 40. Zander E. 1909. Tierische Parasiten als Krankheitserreger bei der Biene, Leipziger

333 Bienenztg. 24: 147-150, 164-166. 


\section{Table 1 (on next page)}

Distribution of $\mathrm{N}$. ceranae in three different regions in Bulgaria. 
1 Table 1. Distribution of $N$. ceranae in three different regions in Bulgaria.

\begin{tabular}{|c|c|c|c|c|c|c|}
\hline Region & No. of & No. of & \%o of & & \\
& samplested & positive & positive & $\begin{array}{c}\text { N. } \\
\text { ceranae }\end{array}$ & N. apis & $\begin{array}{c}\text { Co- } \\
\text { infection }\end{array}$ \\
\hline Smolyan (SB) & 36 & 5 & 13.9 & 5 & - & - \\
\hline Sofia (WB) & 28 & 18 & 64.3 & 18 & - & - \\
\hline Russe (NB) & 44 & 34 & 77.2 & 34 & - & - \\
\hline Total & $\mathbf{1 0 8}$ & $\mathbf{5 7}$ & $\mathbf{5 2 . 8}$ & $\mathbf{5 7}$ & - & - \\
\hline
\end{tabular}

2

3 Abbreviations: SB - South Bulgaria; WB - West Bulgaria; NB - North Bulgaria 
Figure 1

Map showing sampling locations in Bulgaria.

Nosema species distribution are represented in all Balkan countries.

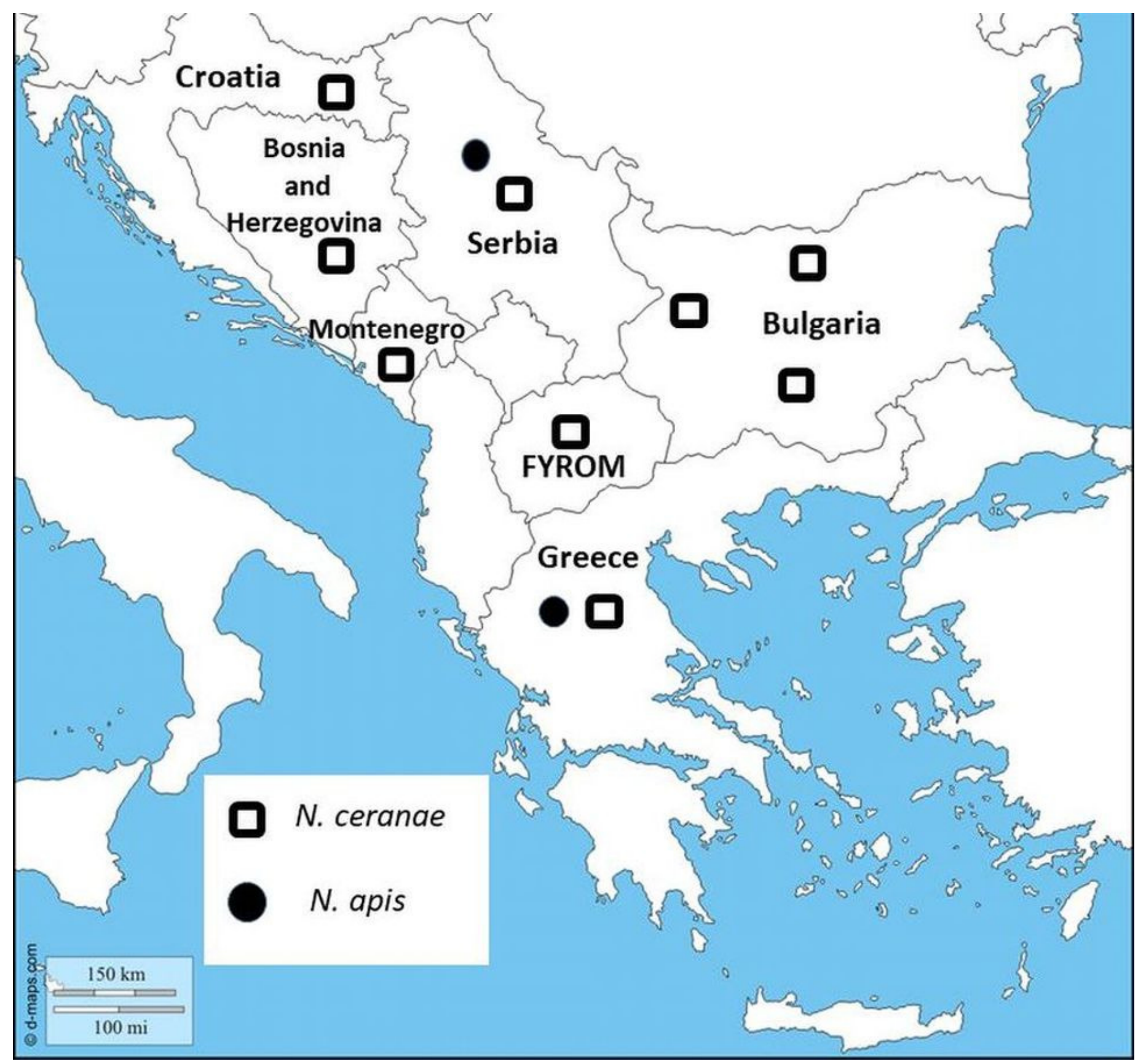

